Revista Brasil. Bot., V.25, n.3, p.339-349, set. 2002

\title{
Distribuição e caracterização anatômica dos coléteres foliares de Prestonia coalita (Vell.) Woodson (Apocynaceae) ${ }^{1}$
}

\author{
MARIA C. SCATOLIN RIO², MARÍLIA M. CASTRO ${ }^{2,3}$ e LUIZA S. KINOSHITA²
}

(recebido: 17 de outubro de 2001; aceito: 29 de maio de 2002)

\begin{abstract}
Distribution and anatomical characterization on the foliar colleters of Prestonia coalita (Vell.) Woodson (Apocynaceae)). A structural study on the foliar colleters of Prestonia coalita (Vell.) Woodson was conducted in order to establish their number and positions, to describe their structure, to determine in which stage of leaf development secretion starts and to comprove the presence of mucilage in its secretion. Each node presented 14-18 intrapetiolar colleters, whose differentiation occurs in the early stages of leaf development, and secretion occurs in leaf primordia with 5-8 mm length. Colleters are constituted by a long head that includes a central core of parenchymatous cells, surrounded by one layered palisade secretory epidermal cells, and a short stalk devoid of any epidermal secretory cells. Multicellular hairs and vascular tissue were observed only in intermediary colleters, which correspond with modified stipules. These structures' identification as colleters is confirmed by the presence of mucilage in secretion. The stipular nature of most colleters is confirmed, while only central colleters are originated from leaf axil.
\end{abstract}

RESUMO - (Distribuição e caracterização anatômica dos coléteres foliares de Prestonia coalita (Vell.) Woodson (Apocynaceae)). Um estudo estrutural dos coléteres foliares de Prestonia coalita (Vell.) Woodson foi realizado com a finalidade de definir o número e a posição ocupada pelos coléteres, caracterizar a sua estrutura, determinar o estádio de desenvolvimento da folha em que eles se encontrem em fase secretora e comprovar a presença de mucilagem na secreção por eles produzida. Em cada nó, 14-18 coléteres intrapeciolares são observados; sua diferenciação ocorre nos estádios iniciais do desenvolvimento foliar e a atividade secretora em primórdios com ca. 5-8 mm de comprimento. Os coléteres são constituídos por uma longa cabeça, formada por um núcleo central de células parenquimáticas rodeado por epiderme uniestratificada secretora em paliçada, e um curto pedúnculo, no qual as células epidérmicas não secretoras apresentam formato cúbico a retangular. Tricomas multicelulares tectores e tecido vascular estão presentes apenas nos coléteres intercalares, que correspondem às estípulas modificadas. A identificacão destas estruturas como coléteres é comprovada devido à presença de mucilagem na secreção. A natureza estipular da maioria dos coléteres é confirmada, enquanto apenas os centrais são originados na região axilar da folha.

Key words - Colleters, leaves, secretion, Prestonia coalita, Apocynaceae

\section{Introdução}

Coléteres são estruturas secretoras que produzem uma substância viscosa, constituída por uma mistura de mucilagem e terpenos, que lubrifica e protege gemas em início de desenvolvimento (Fahn 1979). Estruturalmente, eles podem ser tricomas, emergências ou glândulas, neste caso, se vascularizadas (Fahn 1990). Eles podem estar presentes em órgãos vegetativos, sendo mais comuns em gemas e folhas jovens do que em órgãos adultos, e/ou reprodutivos de diversas famílias de dicotiledôneas (Fahn 1979, Thomas 1991).

1. Parte da tese de mestrado de Maria Carolina Scatolin do Rio, vinculada ao Programa de Pós-graduação em Biologia Vegetal da Universidade Estadual de Campinas.

2. Universidade Estadual de Campinas, Departamento de Botânica, Instituto de Biologia, Caixa Postal 6109, 13083-970 Campinas, SP, Brasil.

3._Autor para correspondência: mariliac@unicamp.br
Devido às semelhanças quanto à estrutura e distribuição dos coléteres encontrados em partes vegetativas, eles podem freqüentemente ser confundidos com nectários extraflorais (Dave \& Patel 1975, Mohan \& Inamdar 1986, Thomas 1991). Somente através da realização de testes químicos, os principais componentes do material secretado são determinados e a estrutura que os produz é identificada; desta forma, a presença de açúcar na secreção dos nectários extraflorais os diferencia dos coléteres, nos quais a mucilagem predomina na secreção (Fahn 1979).

No caso das Apocynaceae s.l., uma família composta por 424 gêneros distribuídos em cinco subfamílias (Endress \& Bruyns 2000), os coléteres presentes nas partes vegetativas constituem-se em emergências ou glândulas persistentes observadas na base da lâmina foliar e na face adaxial da base do pecíolo (Thomas 1991), podendo ocupar posição interpeciolar ou intrapeciolar (Sennblad et al. 1998).

Embora os coléteres sejam estruturas freqüentes nas Apocynaceae, com ocorrência em folhas registrada 
para 50 gêneros (tabela 1), poucos trabalhos relacionados à estrutura, distribuição, desenvolvimento e/ou histoquímica dos coléteres de espécies dessa família foram realizados nos últimos anos, destacando-se aqueles efetuados em Aganosma caryophyllata G. Don. (Dave et al. 1987), Allamanda cathartica L., Alstonia scholaris L., Nerium indicum Mill. (Thomas \& Dave 1989a, b, c), Roupelia grata Wall. (hoje Strophanthus gratus (Wall. et Hook.) Baill. et Arn.; Thomas et al. 1989), Mandevilla illustris (Vell.) Woodson e M. velutina (Mart. ex Stadelm.) Woodson (Appezzato-da-Glória \& Estelita 2000). Podem, ainda, ser mencionados os trabalhos relacionados à ontogênese dos coléteres em Allamanda cathartica e Tabernaemontana divaricata (L.) R. Br. (Ramayya \& Bahadur 1968), ao modo de secreção de coléteres em Alstonia scholaris (Thomas \& Dave 1990) e aos aspectos filogenéticos de coléteres em Apocynaceae (Thomas \& Dave 1991).

$\mathrm{O}$ gênero Prestonia $\mathrm{R}$. Br. pertence à subfamília Apocynoideae Burnett (Endress \& Bruyns 2000) e é constituído por cerca de 60 espécies de lianas com distribuição neotropical, onde podem ser encontrados coléteres na base dos pecíolos e na base dos lobos do cálice (Woodson 1936). Segundo Rio (2001), os coléteres interpeciolares presentes nos nós vegetativos de algumas espécies de Prestonia têm importância taxonômica, sendo utilizados em chave para identificação das espécies ocorrentes nas regiões Sul e Sudeste do Brasil. Uma vez que não há estudos anatômicos referentes aos coléteres encontrados nas espécies de Prestonia, a presente investigação teve por objetivo definir o número e a posição ocupada pelos coléteres foliares de Prestonia coalita (Vell.) Woodson, caracterizar a sua estrutura, determinar o estádio de desenvolvimento da folha em que os coléteres se encontrem em fase secretora e comprovar a presença de mucilagem na secreção produzida por estas estruturas.

\section{Material e métodos}

Para o estudo dos coléteres foliares, um indivíduo de Prestonia coalita (Vell.) Woodson foi coletado em Carrancas, MG. O material testemunha está depositado no Herbário da Universidade Estadual de Campinas (UEC): BRASIL: MinAS GERAIS: Carrancas, 24/II/2000, L.S. Kinoshita et al. 2000.10 (UEC).

O material foi fixado em FAA 50 por $48 \mathrm{~h}$. e estocado em álcool etílico 70\% (Johansen 1940). Os ápices e dois nós subseqüentes foram isolados a partir dos ramos vegetativos.
As peças foram desidratadas pela série butílica (Johansen 1940) e incluídas em paraplast. Os cortes seriados longitudinais e transversais, com $12 \mu \mathrm{m}$ de espessura, foram corados para o estudo estrutural com Safranina (solução alcoólica) 1\% e Azul de Astra (solução aquosa) 1\% (Gerlach 1969) e as lâminas permanentes montadas em resina sintética. Para evidenciar a presença de mucilagem (Gregory \& Baas 1989), os cortes foram corados com Vermelho de Rutênio (solução aquosa) 1:5.000 (Rawlins \& Takahashi 1952) e as lâminas semipermanentes, montadas em gelatina glicerinada.

As fotomicrografias foram obtidas em microscópio Olympus BX 50, com a utilização de filme Kodak Gold $35 \mathrm{~mm}$ asa 100 . As escalas foram obtidas através da projeção de lâmina micrométrica nas mesmas condições ópticas utilizadas para as ilustrações.

\section{Resultados}

Na região nodal do caule de Prestonia coalita, um número variável de coléteres é observado na base da folha ocupando posição intrapeciolar; estes coléteres têm origens independentes e são formados no início do desenvolvimento dos primórdios foliares (figuras 1-15), que apresentam filotaxia oposta. Em cada nó, 14-18 coléteres podem ser encontrados, sete a nove por primórdio, dos quais apenas um ocupa posição axilar e os demais posição marginal (figuras 5, 12).

O mesmo padrão de desenvolvimento dos coléteres se repete em todos os nós estudados; assim, a descrição destas estruturas será efetuada considerando-se o primeiro e segundo nó vegetativo (figuras 1-16) de apenas um lado correspondente à base de um dos dois primórdios foliares opostos, onde podem ser encontrados nove coléteres por nó. A origem de oito (quatro de cada lado) deles se dá na região marginal do primórdio foliar correspondente à estípula (figuras 1-5), e de um (o central), na região axilar do primórdio foliar (asterisco; figuras 3,13-14). Os dois primeiros coléteres (A) começam a se desenvolver na região mediana da estípula (figuras 1-4, 7-8, 14), estando ausentes nas folhas com apenas sete coléteres. Os segundos (B) têm origem na região basal da estípula (figuras 3, 7, 14-15), enquanto os terceiros (C) são formados na região apical (figuras 3-6, 8). Os quartos coléteres (D) ocupam posição intercalar entre os segundos (B) e terceiros (C) coléteres e mantêm a vascularização das estípulas (figuras 3-6, 8-12, 16), diferenciando-se, portanto, dos demais coléteres que não são vascularizados (figura 15). Observa-se a manutenção do feixe vascular durante a diferenciação desses coléteres (figuras 3-6, 8-11). As dimensões dos coléteres foliares de $P$. coalita estão descriminadas na tabela 2. 
Tabela 1. Coléteres foliares presentes nas Apocynaceae s.l.; classificação segundo Endress \& Bruyns (2000). 1 = pecíolo; 2 = lâmina. Dados baseados em Woodson \& Moore (1938), Ramayya \& Bahadur (1968), Fjell (1983), Hansen (1985), Dave et al. (1987), Thomas et al. (1989), Thomas \& Dave (1989a, b, c, 1990, 1991), Thomas (1991), Sennblad et al. (1998), Appezzato-da-Gloria \& Estelita (2000).

\begin{tabular}{|c|c|c|}
\hline Subfamília & Gênero & Posição \\
\hline \multirow[t]{15}{*}{ RAUVOLFIOIDEAE } & Acokanthera & 1 \\
\hline & Allamanda & 1 \\
\hline & Alstonia & 1 \\
\hline & Carissa & 1 \\
\hline & Catharanthus & 1 \\
\hline & Cerbera & 1 \\
\hline & Himatanthus & 1 \\
\hline & Landolphia & 1 \\
\hline & Picralima & 1 \\
\hline & Plumeria & 1 \\
\hline & Rauvolfia & 1 \\
\hline & Tabernaemontana & 1 \\
\hline & Thevetia & 1 \\
\hline & Vallesia & 1 \\
\hline & Vinca & 1 \\
\hline \multirow[t]{20}{*}{ APOCYNOIDEAE } & Adenium & 1 \\
\hline & Aganosma & 1 \\
\hline & Аросупит & 1 \\
\hline & Baissea & 1 \\
\hline & Beaumontia & 1 \\
\hline & Forsteronia & 1,2 \\
\hline & Holarrhena & 1 \\
\hline & Ichnocarpus & 1 \\
\hline & Mandevilla & 1,2 \\
\hline & Nerium & 1 \\
\hline & Parsonsia & 1 \\
\hline & Prestonia & 1 \\
\hline & Roupelia (hoje Strophanthus) & 1 \\
\hline & Stephanostema & 1 \\
\hline & Strophanthus & 1 \\
\hline & Thenardia & 1 \\
\hline & Trachelospermum & 1 \\
\hline & Urceola & 1 \\
\hline & Vallaris & 1 \\
\hline & Wrightia & 1 \\
\hline \multirow[t]{3}{*}{ PERIPLOCOIDEAE } & Cryptolepis & 1 \\
\hline & Cryptostegia & 1 \\
\hline & Periploca & 1 \\
\hline \multirow[t]{2}{*}{ SECAMONOIDEAE } & Secamone & 1 \\
\hline & Toxocarpus & 1 \\
\hline \multirow[t]{11}{*}{ ASCLEPIADOIDEAE } & Calotropis & 1,2 \\
\hline & Ceropegia & 1 \\
\hline & Cynanchum & 1 \\
\hline & Dischidia & 1 \\
\hline & Heterostemma & 1 \\
\hline & Marsdenia & 1 \\
\hline & Oxystelma & 1 \\
\hline & Pentatropis & 1 \\
\hline & Sarcostemma & 1 \\
\hline & Telosma & 2 \\
\hline & Tylophora & 1 \\
\hline
\end{tabular}




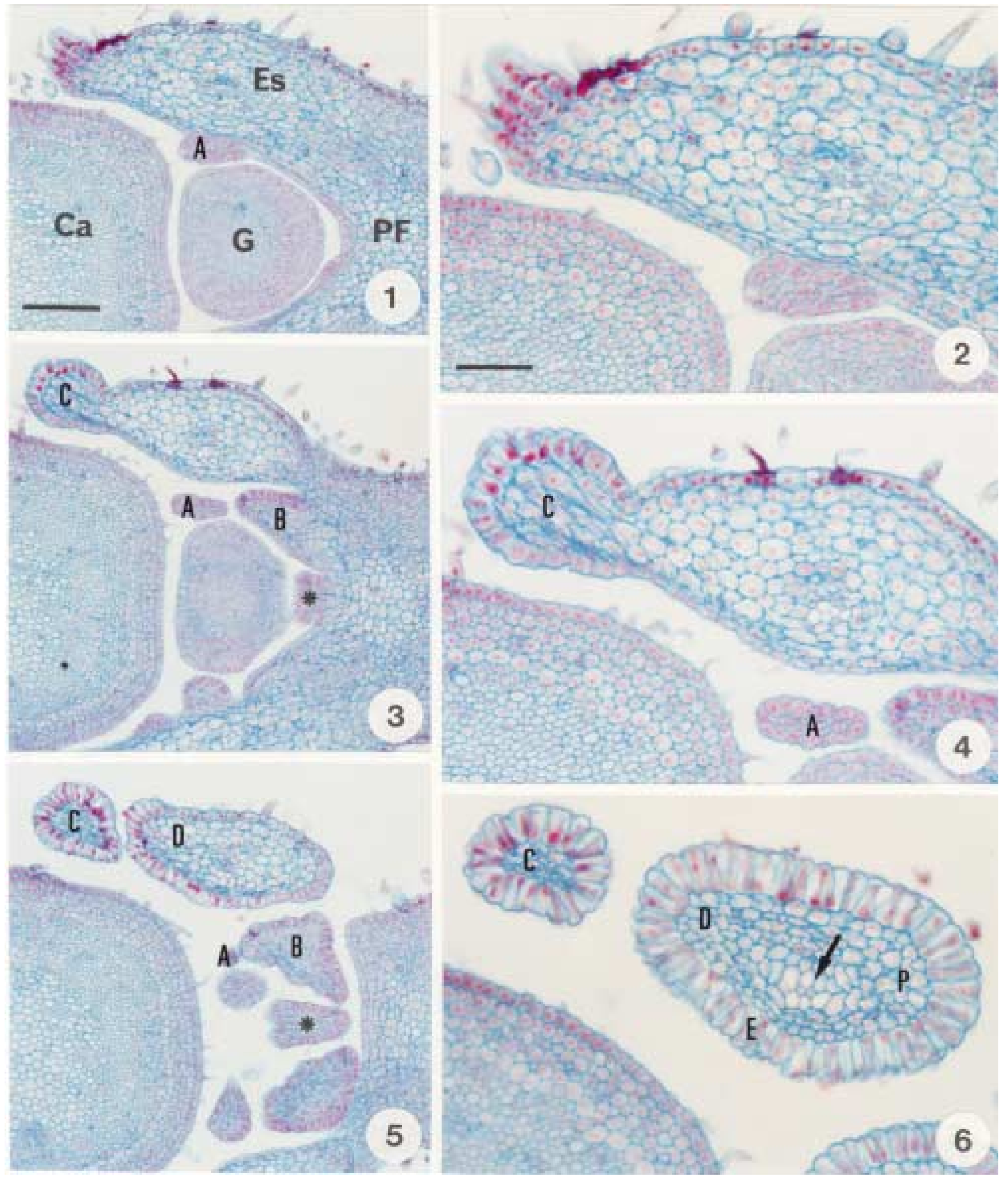

Figuras 1-6. Cortes transversais do primeiro nó. 1-2. Primeiro coléter (A) em diferenciação na região mediana da estípula; 2. Pormenor da figura 1. 3-4. Início do desenvolvimento do coléter central (*) na axila do primórdio foliar, do segundo coléter (B) na base da estípula e do terceiro coléter (C) na região apical da estípula; 4. Pormenor da figura 3. 5. Coléteres de origem estipular (A,B,C,D) e axilar (*) em formação. 6. Terceiro (C) e quarto (D) coléteres diferenciados; o quarto coléter (D) é vascularizado (seta). $\mathrm{Ca}=$ caule; $\mathrm{E}=$ epiderme; $\mathrm{Es}=$ estípula; $\mathrm{G}=$ gema axilar; $\mathrm{P}=$ parênquima; $\mathrm{PF}=$ primórdio foliar. $\mathrm{Barras}$ $=100 \mu \mathrm{m}$ (fig. 1,3,5), $50 \mu \mathrm{m}$ (fig. 2,4,6). 

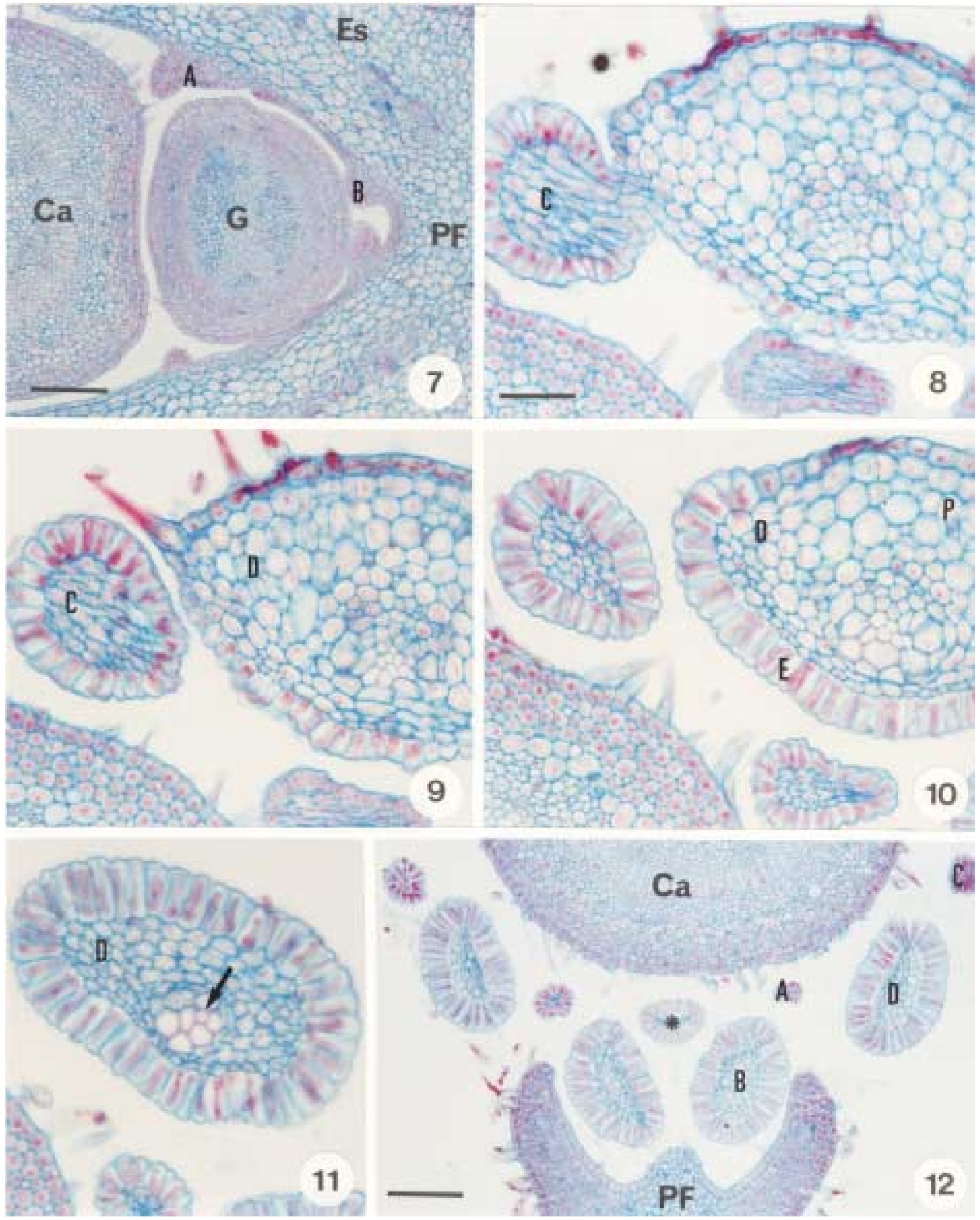

Figuras 7-12. Cortes transversais do segundo nó. 7. Início da formação do primeiro (A) e segundo (B) coléteres; 8-11. Diferenciação do coléter intercalar (D), vascularizado; 8. Região basal, terceiro coléter (C) ainda ligado; 9. Região basal, terceiro coléter (C) já separado; 10. Coléter intercalar (D), epiderme interna em paliçada; 11. Coléter intercalar (D) vascularizado (seta); 12. Distribuição dos coléteres de origem estipular (A,B,C,D) e axilar $\left({ }^{*}\right)$. Ca = caule; $\mathrm{E}=$ epiderme; $\mathrm{Es}=$ estípula; $\mathrm{G}=$ gema axilar; $\mathrm{P}=$ parênquima; $\mathrm{PF}=$ primórdio foliar. Barras $=100 \mu \mathrm{m}$ (figuras 7,12), $50 \mu \mathrm{m}$ (figuras 8-11). 


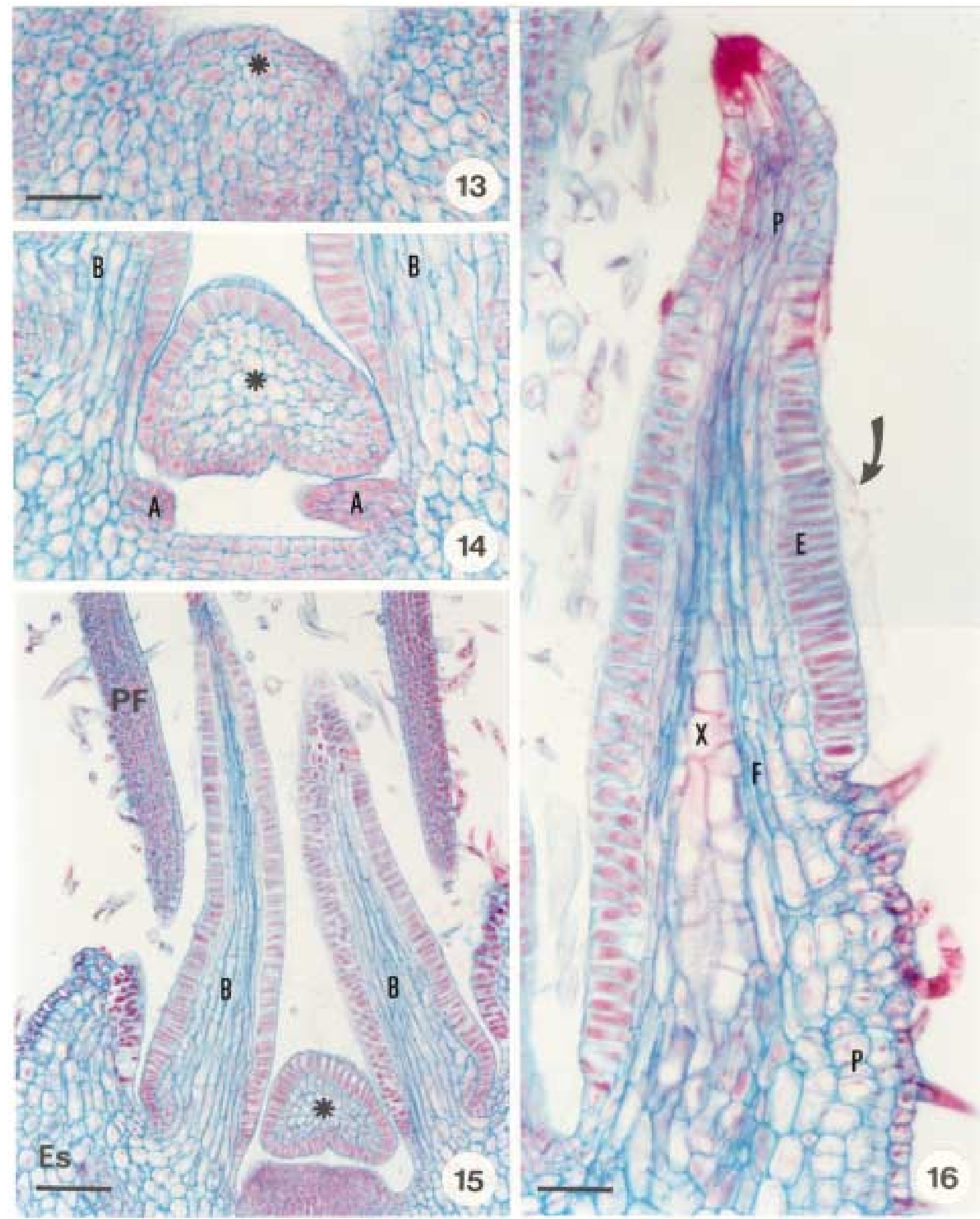

Figuras 13-16. Cortes longitudinais do segundo nó. 13. Coléter central (*) em diferenciação; 14. Pedúnculo do coléter central (*) e base dos primeiros (A) e segundos (B) coléteres. 15-16. Coléteres em seu maior comprimento; secreção acidófila nas células epidérmicas em paliçada e no meio extracelular (seta curva). 15. Segundos coléteres (B); 16. Quarto coléter (D) com tricomas multicelulares tectores e vascularização. $\mathrm{E}=$ epiderme; $\mathrm{Es}=$ estípula; $\mathrm{F}=$ floema; $\mathrm{P}=$ parênquima; $\mathrm{PF}=$ primórdio foliar; $\mathrm{X}=$ xilema. Barras $=50 \mu \mathrm{m}$ (figuras 13,14,16), $100 \mu \mathrm{m}$ (figura 15). 
Tabela 2. Dimensões dos coléteres foliares de Prestonia coalita (Vell.) Woodson.

\begin{tabular}{lccc}
\hline Posição dos coléteres & $\begin{array}{c}\text { Comprimento } \\
(\mu \mathrm{m})\end{array}$ & $\begin{array}{c}\text { Largura } \\
(\mu \mathrm{m})\end{array}$ \\
\hline Marginal & $\mathrm{A}$ & $120-300$ & $80-100$ \\
& $\mathrm{~B}$ & $850-1000$ & $180-200$ \\
& $\mathrm{C}$ & $380-450$ & 100 \\
& $\mathrm{D}$ & $650-800$ & 360 \\
Central & & $400-500$ & 160 \\
\hline
\end{tabular}

Todos os coléteres foliares são constituídos por uma cabeça longa, formada por um núcleo central de células parenquimáticas rodeado por uma epiderme secretora uniestratificada em paliçada, sobre um pedúnculo curto, no qual as células epidérmicas não secretoras têm formato cúbico a retangular. A cabeça apresenta um formato cônico, pontiagudo no ápice, enquanto o pedúnculo pode estar reduzido não apresentando estreitamento (figuras 15-16, 21). Todo o coléter é recoberto por uma fina cutícula e o tecido vascular está presente apenas nos quartos coléteres (D), que ocupam posição intercalar; nestes coléteres, tricomas multicelulares tectores também foram observados (figuras 16, 22), sendo os únicos dentre todos os coléteres foliares que apresentaram modificações estruturais. As células epidérmicas em paliçada da cabeça do coléter, responsáveis pela secreção do exsudato, têm paredes celulares finas, núcleo relativamente grande e citoplasma denso, características comuns a células secretoras (figuras 10-11, 16). Uma secreção acidófila foi evidenciada pela Safranina tanto no interior das células epidérmicas quanto no meio extracelular (seta curva; figura 16) de coléteres do segundo nó, nos quais células com citoplasma de aspecto denso e outras com retração do protoplasto também podem ser observadas (figuras 10-11, 16).

A presença de mucilagem foi evidenciada no meio extracelular (seta curva; figuras 18-20,23) e no interior das células epidérmicas em paliçada que recobrem a cabeça de todos os coléteres observados (figuras 17-23), tanto no segundo (primórdios foliares com ca. $5 \mathrm{~mm}$ de comprimento) quanto no terceiro nó vegetativo (primórdios foliares com ca. $8 \mathrm{~mm}$ ). Essas células secretoras apresentam citoplasma com conteúdo de aspecto denso ou, então, retração do protoplasto (figuras 18-20), sinal de liberação da secreção; porém, o rompimento da cutícula não foi observado. Em corte longitudinal (figura 21), o material produzido pelas células secretoras, que ocupam as regiões apical e mediana da cabeça dos coléteres, ainda se encontra em seu interior; tais células não apresentam retração do citoplasma, como as células da região basal da cabeça do coléter. Não há indícios de atividade secretora nas células do pedúnculo (figura 21).

\section{Discussão}

Coléteres em folhas já foram observados em espécies pertencentes a 19 gêneros da subfamília Apocynoideae, com duas ocorrências para lâmina foliar em Forsteronia e Mandevilla, e as demais para pecíolo em espécies de Adenium, Aganosma, Apocynum, Baissea, Beaumontia, Forsteronia, Holarrhena, Ichnocarpus, Mandevilla, Nerium, Parsonsia, Prestonia, Stephanostema, Strophanthus, Thenardia, Trachelospermum, Urceola, Vallaris e Wrightia (Hansen 1985, Dave et al. 1987, Thomas et al. 1989, Thomas \& Dave 1989c, 1991, Thomas 1991, Sennblad et al. 1998, Appezzato-da-Glória \& Estelita 2000). Em Prestonia, os coléteres foliares foram observados e macromorfologicamente descritos para as 15 espécies ocorrentes nas regiões Sul e Sudeste do Brasil (Rio 2001).

Em Prestonia coalita, cada folha possui de sete a nove coléteres intrapeciolares. Variações no número de coléteres nas folhas de uma mesma espécie já foram registradas para a família. Ramayya \& Bahadur (1968) observaram 10-13 coléteres foliares em Allamanda cathartica, enquanto Thomas \& Dave (1989a) registraram apenas quatro a seis coléteres foliares para esta espécie. Em Thevetia peruviana (Pers.) K. Schum (= T. neriifolia Juss.), Hifny Saber et al. (1969 apud Thomas 1991) mencionaram oito a dez coléteres peciolares e Fjell (1983) registrou 14-18 coléteres peciolares para esta espécie. Segundo Thomas (1991), o número dos coléteres de uma espécie pode variar com a distribuição geográfica.

Embora o número e a posição dos coléteres já tenham sido referidos como caracteres taxonômicos relevantes para as Apocynaceae (Woodson \& Moore 1938), tais aspectos têm sido pouco considerados nos estudos efetuados em partes vegetativas. A presença de coléteres interpeciolares foi uma característica utilizada na chave para a identificação das 15 espécies de Prestonia ocorrentes nas regiões Sul e Sudeste do Brasil (Rio 2001). P. solanifolia (Müll. Arg.) Woodson foi diferenciada de $P$. coalita e de $P$. dusenii (Malme) Woodson, espécies intimamente relacionadas quanto à morfologia floral, assim como P. calycina Müll. Arg. 


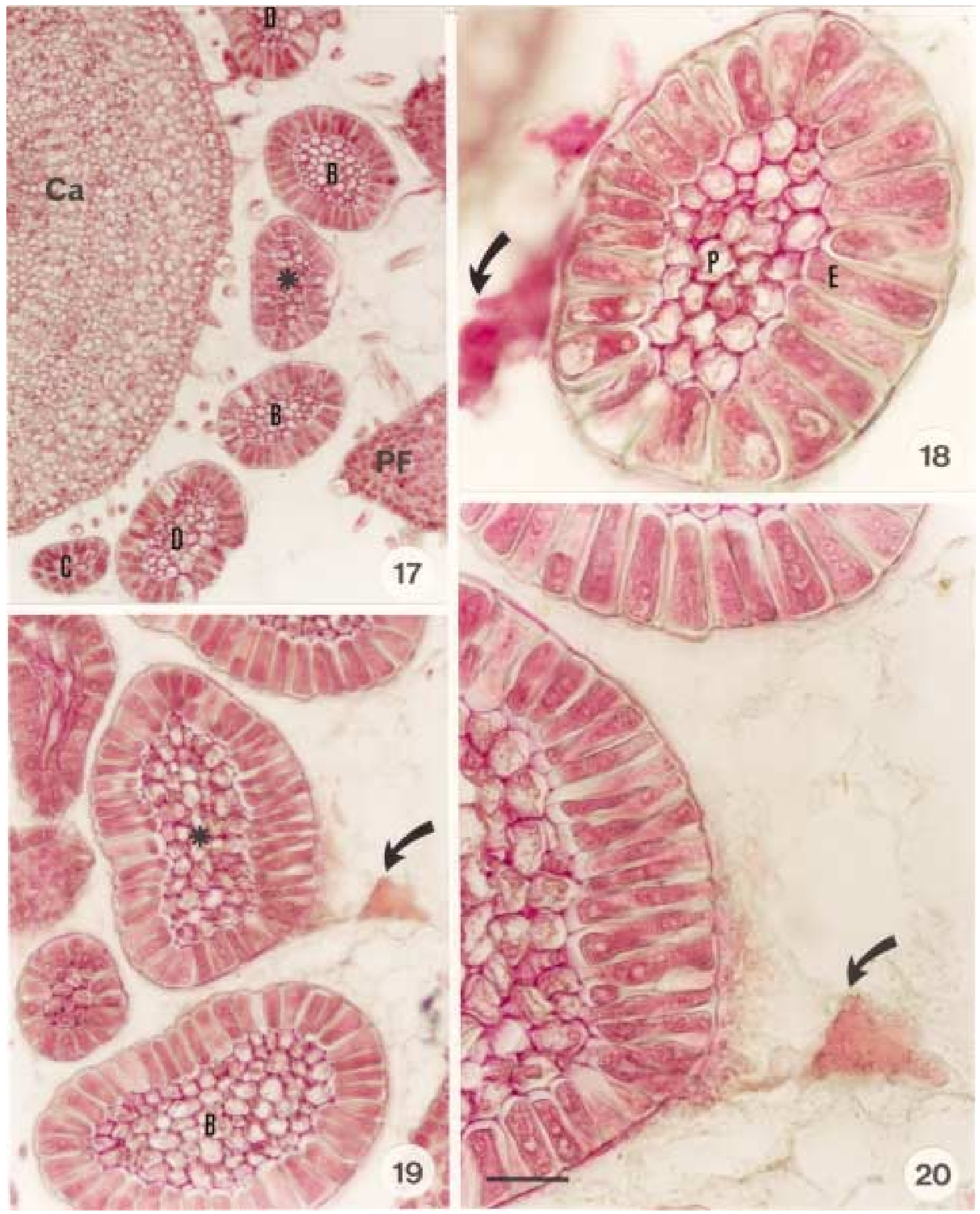

Figuras 17-20. Cortes transversais do terceiro nó; mucilagem evidenciada pelo Vermelho de Rutênio nas células epidérmicas em paliçada ou no meio extracelular (seta curva). 17. Coléteres estipulares (B,C,D) e central (*); 18. Coléter estipular (B). 19-20. Coléter estipular (B) e central (*); 20. Pormenor da figura 19. $\mathrm{Ca}=$ caule; $\mathrm{E}=$ epiderme; $\mathrm{P}=$ parênquima; $\mathrm{PF}=$ primórdio foliar. Barra $=100 \mu \mathrm{m}$ (figura 17), $25 \mu \mathrm{m}$ (figuras 18,20), $50 \mu \mathrm{m}$ (figura 19). 


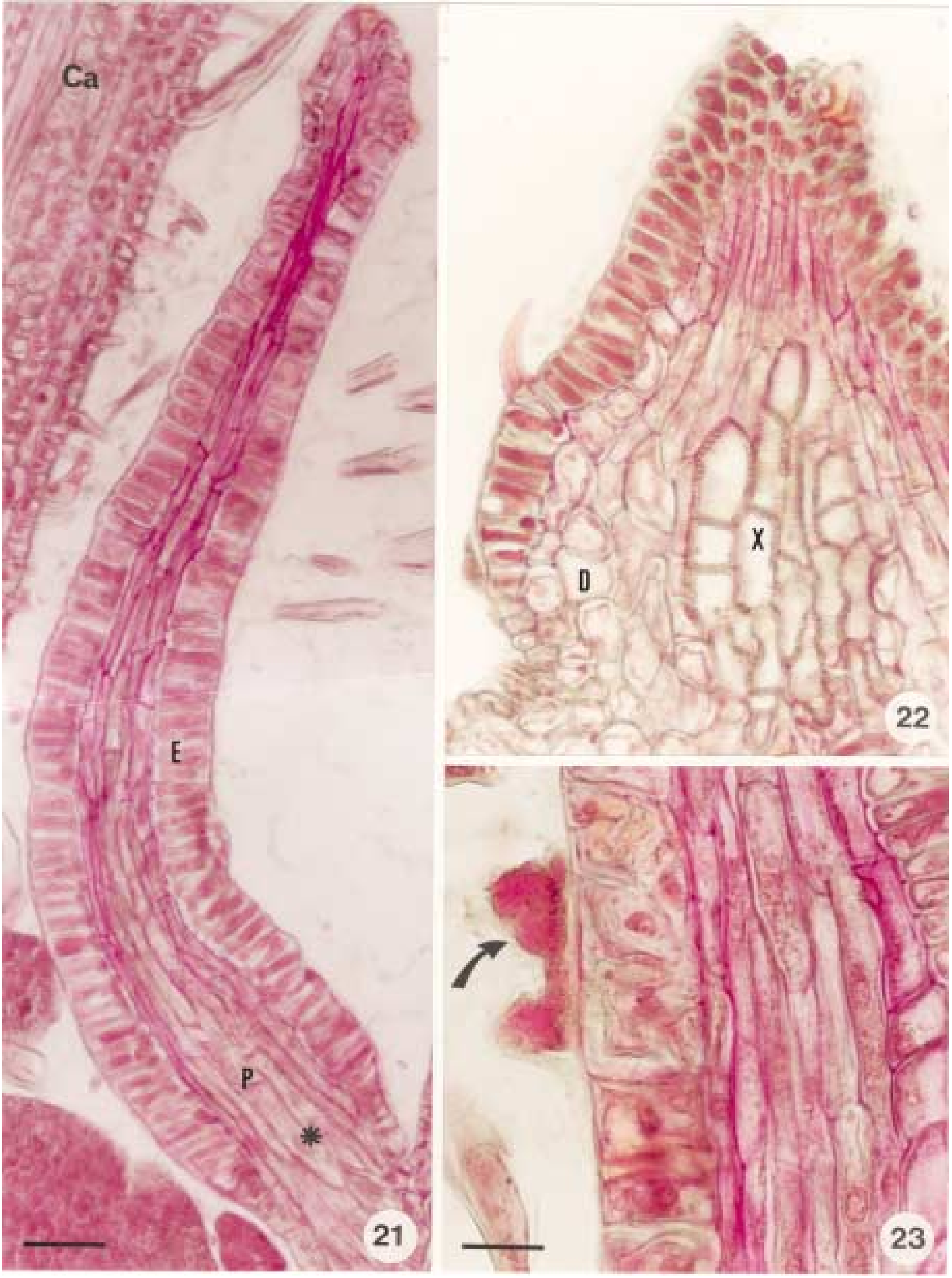

Figuras 21-23. Cortes longitudinais do terceiro nó; mucilagem evidenciada pelo Vermelho de Rutênio nas células epidérmicas em paliçada ou no meio extracelular (seta curva). 21. Coléter central (*); 22. Coléter intercalar (D); 23. Coléter estipular (B). $\mathrm{Ca}=$ caule; $\mathrm{E}=$ epiderme; $\mathrm{P}=$ parênquima; $\mathrm{X}=$ xilema. Barras $=50 \mu \mathrm{m}$ (figuras 21-22); $25 \mu \mathrm{m}$ (figura 23 ). 
foi separada das demais espécies com indumento abundante nas folhas, por apresentarem coléteres interpeciolares. Da mesma forma, P. perplexa Woodson e P. denticulata (Vell.) Woodson foram distintas das demais espécies com apêndices supra-estaminais e folhas glabras a levemente papiladas pela presença de coléteres interpeciolares, sendo posteriormente diferenciadas por caracteres foliares e florais.

Os coléteres foliares de Prestonia coalita são do tipo padrão ("standard" - S) descrito por Lestern (1974), caracterizado pela presença de uma cabeça alongada recoberta por epiderme secretora em paliçada e um pedúnculo curto sem células secretoras. Apesar de ter sido proposta para coléteres encontrados em espécies de Rubiaceae, a terminologia definida por Lestern (1974) tem sido utilizada para a descrição dos coléteres de diversas famílias, inclusive Apocynaceae (Thomas 1991, Appezzato-da-Glória \& Estelita 2000).

Quanto à presença de tecido vascular, somente os coléteres intercalares de $P$. coalita são vascularizados por reterem a vascularização da estípula; os demais coléteres, inclusive os de maior tamanho, não são vascularizados. Este é o primeiro registro de coléteres vascularizados para Prestonia. Coléteres foliares vascularizados ocorrem em Aganosma caryophyllata (Dave et al. 1987), Mandevilla illustris e M. velutina (Appezzato-da-Glória \& Estelita 2000). Os coléteres de Nerium oleander L. (Williams et al. 1982), Allamanda cathartica (Thomas \& Dave 1989a) e Roupelia grata (Thomas et al. 1989) não apresentaram tecido vascular. Ressalta-se a importância de analisar os coléteres através de cortes seriados transversais e longitudinais, tanto para a constatação da ocorrência de vascularização, que dependendo do plano do corte pode ou não estar evidente (Appezzato-da-Glória \& Estelita 2000), quanto para a definição do número real de coléteres encontrado por peça.

Dentre as modificações estruturais (presença de tricomas, células subepidérmicas procumbentes e laticíferos) já registradas para coléteres da família Apocynaceae (Thomas 1991), apenas tricomas multicelulares tectores foram encontrados exclusivamente nos coléteres intercalares derivados diretamente da estípula de Prestonia coalita. Tricomas unicelulares já foram registrados para Aganosma caryophyllata (Dave et al. 1987), enquanto Roupelia grata (Thomas et al. 1989) e Nerium indicum (Thomas \& Dave 1989c) apresentaram uma camada de células subepidérmicas alongadas radialmente. Apenas laticíferos foram encontrados em Allamanda cathartica (Thomas \& Dave 1989a). Thomas \& Dave (1991) consideraram as modificações estruturais, assim como a vascularização, representantes de um passo evolutivo entre os coléteres de Apocynaceae.

Em cada folha de Prestonia coalita, um único coléter tem origem na região axilar do primórdio foliar, enquanto que os demais são originados a partir de expansões laterais da base do primórdio foliar (estípulas). Dessa forma, a natureza estipular é confirmada para a maioria dos coléteres foliares de P. coalita. Woodson \& Moore (1938) propuseram a teoria estipular para os coléteres de Apocynaceae, considerando que tanto os coléteres dos nós vegetativos quanto os calicinais pertenceriam à categoria de estípulas. Considerando a presença de coléteres axilares em $P$. coalita, o estudo dos coléteres nodais deveria ser estendido para outras espécies de Apocynaceae com o propósito de reavaliar a teoria proposta por Woodson \& Moore (1938). A retenção dos coléteres com tendência à redução das estípulas foi observada em todas as famílias da ordem Gentianales (Thomas 1991).

A secreção dos coléteres de Prestonia coalita pode ser encontrada em estádios muito iniciais do desenvolvimento da folha (primórdios de 5 a $8 \mathrm{~mm}$ ), sendo constituída por mucilagem. Segundo Thomas (1991), os coléteres começam a secretar antes da expansão da lâmina foliar, o que foi confirmado em $P$. coalita. A natureza mucilaginosa da secreção e a fase inicial do desenvolvimento foliar em que os coléteres são encontrados em atividade secretora estão relacionadas à função que essas estruturas desempenham, que é a de lubrificar e proteger gemas e, conseqüentemente, meristemas em início de desenvolvimento (Fahn 1979).

Agradecimentos - Os autores agradecem à Fundação de Amparo à Pesquisa do Estado de São Paulo (Fapesp) pelas bolsas concedidas (proc. n. 96/10106-3, 99/01768-0) e ao Fundo de Apoio à Pesquisa da Universidade Estadual de Campinas (FAEP/Unicamp) pelo auxílio à publicação das pranchas coloridas (sol. n. 0612/02).

\section{Referências bibliográficas}

APPEZZATO-DA-GLÓRIA, B. \& ESTELITA, M.E.M. 2000. Development, structure and distribution of colleters in Mandevilla illustris e M. velutina (Apocynaceae). Revista Brasileira de Botânica 23:113-120.

DAVE, Y.S. \& PATEL, N.D. 1975. A developmental study of extrafloral nectaries in slipper spurge (Pedilanthus tithymaloides, Euphorbiaceae). American Journal of Botany 62:808-812. 
DAVE, Y., THOMAS, V. \& KURIACHEN, P.M. 1987. Structure and development of colleters of Aganosma caryophyllata G. Don. Pakistan Journal of Botany 19:243-248.

ENDRESS, M.E. \& BRUYNS, P.V. 2000. A revised classification of Apocynaceae s.l. The Botanical Review 66:1-56.

FAHN, A. 1979. Secretory tissues in plants. Academic Press Inc., London.

FAHN, A. 1990. Plant anatomy. $4^{\text {th }}$ ed. Pergamon Press, Oxford.

FJELL, I. 1983. Anatomy of the xeromorphic leaves of Allamanda neriifolia, Thevetia peruviana and Vinca minor (Apocynaceae). Nordic Journal of Botany 3:383-392.

GERLACH, G. 1969. Botanische mikrotechnik, eine linfuhrung. Georg Thieme, Stuttgard.

GREGORY, M. \& BAAS, P. 1989. A survey of mucilage cells in vegetative organs of the dicotyledons. Israel Journal of Botany 38:125-174.

HANSEN, B.F. 1985. A monographic revision of Forsteronia (Apocynaceae). PhD Thesis, University of South Florida, Florida.

JOHANSEN, D.A. 1940. Plant microtechnique. McGrawHill Book Co., New York.

LESTERN, N.R. 1974. Morphology and distribution of colleters and cristals in relation to the taxonomy and bacterial leaf nodule symbiosis of Psychotria (Rubiaceae). American Journal of Botany 61:973-981.

MOHAN, J.S.S. \& INAMDAR, J.A. 1986. Ultrastructure and secretion of the extrafloral nectaries of Plumeria rubra. Annals of Botany 57:389-401.

RAMAYYA, N. \& BAHADUR, B. 1968. Morphology of the "squamellae" in the light of their ontogeny. Current Science 18:520-522.

RAWLINS, T.E. \& TAKAHASHI, W.N. 1952. Technics of plant histochemistry and virology. The National Press, Milbrae.
RIO, M.C.S. do 2001. Estudos taxonômicos e anatômicos do gênero Prestonia R. Br. nom. cons. (Apocynaceae). Tese de mestrado, Universidade Estadual de Campinas, Campinas.

SENNBLAD, B., ENDRESS, M.E. \& BREMER, B. 1998. Morphology and molecular data in phylogenetic fraternity: the tribe Wrightieae (Apocynaceae) revisited. American Journal of Botany 85:1143-1158.

THOMAS, V. 1991. Structural, fuctional and phylogenetic aspects of the colleter. Annals of Botany 68:287-305.

THOMAS, V. \& DAVE, Y. 1989a. Histochemistry and senescence of colleters of Allamanda cathartica $\mathrm{L}$. (Apocynaceae). Annals of Botany 64:201-203.

THOMAS, V. \& DAVE, Y. 1989b. The colleters of Alstonia scholaris L. (Apocynaceae). Indian Botanical Contactor 6:25-29.

THOMAS, V. \& DAVE, Y. 1989c. Structure, origin, development and senescence of colleters in Nerium indicum Mill. (N. odorum Soland., Apocynaceae). Korean Journal of Botany 32:163-172.

THOMAS, V. \& DAVE, Y. 1990. Mode of secretion in the colleters of Alstonia scholaris (Apocynaceae). Phyton 30:209-212.

THOMAS, V. \& DAVE, Y. 1991. Comparative and phylogenetic significance of colleters in Apocynaceae. Feddes Repertorium 102:23-28.

THOMAS, V., DAVE, Y. \& MENON, A.R.S. 1989. Anatomy and histochemistry of colleters in Roupelia grata (Apocynaceae). Nordic Journal of Botany 8:493-496.

WILLIAMS, R.F., METCALFE, R.A. \& GUST, L.W. 1982. The genesis of form in oleander (Nerium oleander L. ). Australian Journal of Botany 30:677-687.

WOODSON, R.E. 1936. Studies in the Apocynaceae. IV. The American genera of Echitoideae. Annals of the Missouri Botanical Garden 23:169-548.

WOODSON, R.E. \& MOORE, J.A. 1938. The vascular anatomy and comparative morphology of apocynaceous flowers. Bulletin of the Torrey Botanical Club 65:135-165. 